\title{
Using paired teaching for earthquake education in schools
}

\author{
Solmaz Mohadjer ${ }^{1,4}$, Sebastian G. Mutz ${ }^{1}$, Matthew Kemp ${ }^{2}$, Sophie J. Gill ${ }^{2}$, Anatoly Ischuk ${ }^{3}$, and Todd A. Ehlers ${ }^{1}$ \\ ${ }^{1}$ Department of Geosciences, University of Tübingen, Tübingen 72074, Germany \\ ${ }^{2}$ Department of Earth Sciences, University of Oxford, Oxford OX1 3AN, United Kingdom \\ ${ }^{3}$ Institute of Geology, Earthquake Engineering and Seismology, Academy of Sciences of the Republic of Tajikistan, \\ Dushanbe 734063, Tajikistan \\ ${ }^{4}$ Earth and Environmental Sciences, University of Central Asia, Khorog 736000, Tajikistan
}

Correspondence: Solmaz Mohadjer (solmaz.mohadjer@ucentralasia.org)

Received: 23 October 2020 - Discussion started: 13 November 2020

Revised: 22 February 2021 - Accepted: 6 April 2021 - Published: 26 May 2021

Abstract. In this study, we have created 10 geoscience video lessons that follow the paired-teaching pedagogical approach. This method is used to supplement the standard school curriculum with video lessons, instructed by geoscientists from around the world, coupled with activities carried out under the guidance of classroom teachers. The video lessons introduce students to the scientific concepts behind earthquakes (e.g. the Earth's interior, plate tectonics, faulting, and seismic energy), earthquake hazards, and mitigation measures (e.g. liquefaction, structural, and nonstructural earthquake hazards). These concepts are taught through hands-on learning, where students use everyday materials to build models to visualize basic Earth processes that produce earthquakes and explore the effects of different hazards. To evaluate the effectiveness of these virtual lessons, we tested our videos in school classrooms in Dushanbe (Tajikistan) and London (United Kingdom). Before and after the video implementations, students completed questionnaires that probed their knowledge on topics covered by each video, including the Earth's interior, tectonic plate boundaries, and non-structural hazards.

Our assessment results indicate that, while the pairedteaching video lessons appear to enhance student knowledge and understanding of some concepts (e.g. Earth's interior, earthquake location forecasting, and non-structural hazards), they bring little change to their views on the causes of earthquakes and their relation to plate boundaries. In general, the difference between UK and Tajik students' level of knowledge prior to and after video testing is more significant than the difference between pre- and post-knowledge for each group. This could be due to several factors affecting curriculum testing (e.g. level of teachers' participation and classroom culture) and students' learning of content (e.g. preexisting hazards knowledge and experience). To maximize the impact of school-based risk reduction education, curriculum developers must move beyond innovative content and pedagogical approaches, take classroom culture into consideration, and instil skills needed for participatory learning and discovery.

\section{Introduction}

The impacts of earthquake disasters are not only physical, psychological, and economic but also educational. Approximately 1.2 billion students are enrolled in primary and secondary schools, with about 875 million living in high seismic zones (UNICEF, 2014). Recent devastating earthquakes, such as those that struck Pakistan in 2005, China in 2008, Haiti in 2010, and Nepal in 2015 have demonstrated how vulnerable school communities are to earthquake disasters (Fig. 1). In the most affected regions, these earthquakes resulted in the collapse of over $80 \%$ of schools (Pazzi et al., 2016). In China alone, the Wenchuan earthquake destroyed more than 7000 school buildings and significantly damaged more than 10000 . The number of school children affected was estimated to be in the millions. Similarly, in Pakistan, UNICEF reported at least 17000 school children were killed, most of them in the collapse of more than 7500 school buildings, and about 2000 teachers lost their lives, were seriously injured, or displaced (Wisner, 2005; Halvorson and Hamilton, 2010). 


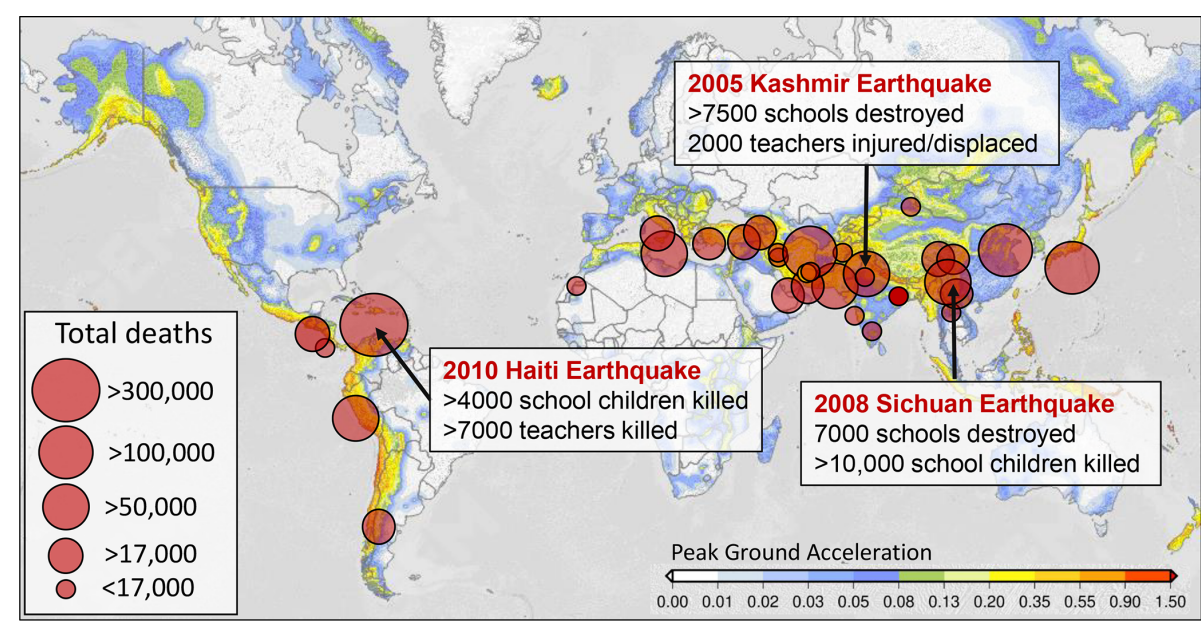

Figure 1. Significant earthquakes from the National Geophysical Data Center/World Data Service (last access: 3 March 2020) superimposed on the Global Seismic Hazard map of Pagani et al. (2018). Impact details of recent earthquakes discussed in text are shown in white boxes.

Scarce resources, inadequate building codes, and unskilled building professionals are often cited as the underlying drivers for unsafe school buildings (Sharma et al., 2016; Bilham and Gaur, 2013; Erdik and Durukal, 2008). Other contributing factors include a lack of science-based earthquake education, awareness of hazards and mitigation measures, and sociocultural factors influencing knowledge, beliefs, and practices (Lownsbery and Flick, 2020; Cavlazoglu and Stuessy, 2017; Halvorson and Hamilton, 2007). In some societies, the lack of access to science-based earthquake information can hinder preparedness by cultivating misconceptions, such as those relating to fatalism and God's will (Yari et al., 2019; Paradise, 2005) or by blaming and shaming specific population groups (Simpson, 2011; Halvorson and Hamilton, 2007). Previous work has identified schoolbased disaster risk reduction (DRR) education as one of the main contributors to the long-term resilience and empowerment of communities (Subedi et al., 2020; Oktari et al., 2018; UNICEF, 2014; Twigg, 2009). An effective DRR curriculum can prepare children and youth to be agents of change by actively engaging them in learning about geohazard science and school safety measures and preparing them to share their learning with the wider community (see Mitchell et al., 2009, and references therein). However, many schools around the world lack the resources and incentives that are required for successful, school-based DRR education, for example, curricular resources and trained teachers. This study aims to improve teachers' access to DRR content, focusing on earthquake education, and to facilitate content teaching by connecting teachers with Earth scientists.

Different approaches to school-based DRR curriculum are summarized in a comprehensive report by the United Nations Children's Fund (UNICEF) and United Nations Educational, Scientific, and Cultural Organization (UNESCO), which includes case studies from 30 countries (Selby and
Kagawa, 2012). In general, curriculum development and integration are textbook driven and/or carried out as co- or extra-curricular activities in the form of pilot projects or special events in schools (e.g. earthquake drills or playing serious games). While some DRR content is easily woven into specific school subjects, such as geography or natural sciences, a textbook-driven approach hinders the achievement of the skills and attitudinal and action learning outcomes required for effective DRR learning. Co-curricular and extra-curricular activities, on the other hand, can provide a means for innovative teaching and interactive and participatory learning.

Here, we apply an innovative teaching technique, known as paired teaching, to create a series of video lessons taught by a scientist and the in-class teacher to enhance sciencebased earthquake education that also covers topics related to earthquake hazards and safety measures. We share the results of our curriculum classroom testing in schools in Tajikistan and the United Kingdom, where natural hazard topics are often textbook driven and discussed briefly, with no or little active learning exercises. The video lessons, therefore, are an opportunity to ignite active learning in school classrooms and allow an opportunity to bring scientists into school classrooms (as video teachers) without additional resources.

\section{Methods}

We created and published 10 free (AttributionNonCommercial Creative Commons license) online video lessons. The videos are archived in the Technische Informations Bibliothek (TIB) AV-Portal (https://doi.org/10.5446/47600) and can be accessed via the YouTube channel of the European Geosciences Union (https://www.youtube.com/user/EuroGeosciencesUnion, last access: 19 May 2021). The video series was created 
collaboratively by nine early career Earth and environmental scientists and educators from academic institutions across the United Kingdom and Germany. Many of the video presenters are experienced educators who have developed and taught science, technology, engineering, and mathematics (STEM)-related subjects and activities in both formal and informal settings, including K-12 schools. To create the series, we adapted the protocols for creating interactive videos by Larson and Murray (2017) and applied them to lessons plans developed by Mohadjer et al. (2010). These protocols incorporate the paired-teaching pedagogy (see Sect. 2.1) and blend well with the interactive exercises that accompany the lesson plans. For a thorough discussion on the protocols, we refer readers to Larson and Murray (2017).

The video lessons are not intended to replace an existing curriculum but rather to support the teaching of concepts related to earthquakes through interactive, hands-on activities and discussions that are guided by a guest scientist and the in-class teacher. In addition, the videos are developed for the global school community and do not target or adhere to the educational standards of a specific region or country. However, teachers are encouraged to contextualize the curriculum content according to their local environment and are given relevant guidelines in the teacher segment at the end of each video (see the Supplement for more details). Below, we introduce the paired-teaching approach and describe our video evaluation strategy.

\subsection{Paired-teaching pedagogy}

We used a pedagogical model known as paired teaching (or teaching duet) developed by the MIT (Massachusetts Institute of Technology) BLOSSOMS (Blended Learning Open Source Science or Math Studies) initiative. This approach enables scientists and educators from around the world to create and instruct virtual lessons and activities that are carried out under the guidance of in-class teachers in school classrooms. A typical virtual lesson contains four to six short video segments taught by the video teacher. Each segment is followed by a live, active-learning segment in the classroom, guided by the in-class teacher. For example, the class starts with segment 1 of a learning video. Towards the end of this segment, the video teacher gives a challenge to the class. The video fades to black and is replaced by a still image of the activity instructions or questions. The in-class teacher pauses the video, and guides the students in an active-learning exercise in the classroom. After the exercise is concluded, the in-class teacher resumes the video, allowing the video teacher to take over the teaching again. The passing of teaching between the in-class and video teachers is a type of blended learning referred to as paired teaching. Figure 2 shows the workflow of our paired-teaching approach. See the Supplement for an example of a video module from our earthquake video series.

In this study, the above technique was adapted and applied to the earthquake education lesson plans of Mohadjer

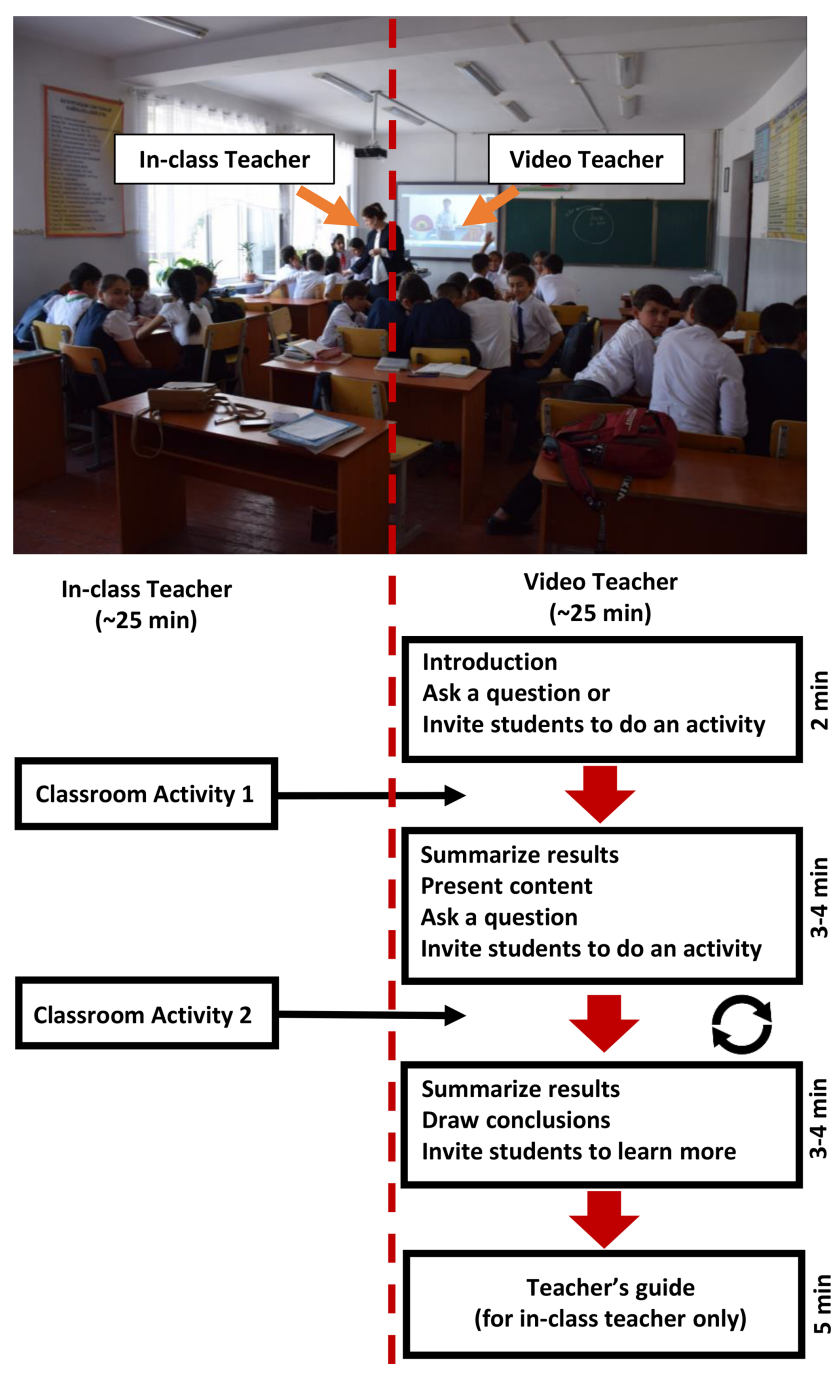

Figure 2. Paired teaching pedagogy. The circular arrows demonstrate the passing of teaching between the in-class and video teachers.

et al. (2010). These lesson plans have been tested, evaluated, and improved by Teachers Without Borders and other educational institutions in the training and guidance of teachers to facilitate DRR learning in schools in China, Tajikistan, Afghanistan, India, and Haiti. To turn these lesson plans into learning videos, we followed the protocols created and used by MIT BLOSSOMS (2021) to produce $>100$ STEM videos. The protocols included the following three key steps before the videotaping began: (1) the writing of the concept for the video lesson, (2) mapping out the structure and content of the video lesson, and (3) preparing a pseudo-script to show how the video lesson will be presented when taped. The lesson plans and learning videos cover similar topics, but they differ in teaching pedagogy (paired teaching vs. the 5E instructional model of Bybee et al., 2006) and the delivery method (video lessons vs. lesson plans). 


\subsection{Curriculum evaluation}

To evaluate the effectiveness of our video series, we selected and tested three video lessons with school students and teachers in Tajikistan and the United Kingdom. We compared pre- and post-assessment data collected from students on the first and last days of the video implementation, respectively. This was done by using a questionnaire that assessed students' learning of main concepts covered in each video that was selected for classroom implementation. This comparison is possible since students answered the same questions in the pre- and post-assessment questionnaires. Ethical approval for this study was sought and received from the participating schools and institutional partners that coordinated this effort in 2018-2019. The ethical procedures were designed to adhere to current standards of assent and consent regarding in-school research and to provide participants with anonymity. As a low-risk, school-based study focused on learning outcomes from regular teaching activities, the consent of the school-based stakeholders, i.e. the principals and teachers, was considered sufficient to proceed with the pre- and post-tests. All participation was voluntary, and students were given the opportunity to assent or refuse participation at both the pre- and post-test points. The pre- and post-tests were anonymous, with students creating their own codenames, which were known only to them, that were used to match the pre- and post-tests for analysis purposes. No sensitive or identifying information was collected, and the anonymous data are stored in a secure location within the European Union that is password protected, in accordance with General Data Protection Regulation (GDPR) regulations. The data will be destroyed upon completion of this research project. Below, we describe the questionnaire, our video selection, and the test sites.

\subsubsection{Pre- and post-assessment questionnaires}

The questionnaire (see the Supplement) contained seven questions, with each question designed to evaluate students' learning of a topic that was explored in selected videos. To elicit a wide range of responses from the students, we used open-ended questions (e.g. "what are the causes of earthquakes?"), drawing strategies (e.g. "draw the Earth's interior") and analysis of photographs (e.g. "can you identify non-structural hazards in each photo?"). We also included questions requiring "yes" or "no" answers (e.g. "can earthquakes be predicted?"). For these questions, we included "I don't know" and "other (please specify)" in the answers from which to select. The only demographic information collected was student gender. To anonymously link the pre- with postassessment data collected from each individual student, we asked students to create a confidential identifier unique to themselves and write it on both pre- and post-assessment questionnaires. Using this method, we were able to collect data from a total of 77 students from Tajikistan and the UK.

\subsubsection{Data analysis}

Students' written responses to survey questionnaires were first categorized into appropriate groups, based on the individual response to each question. We then assigned a score value to each response group, indicating the level of understanding associated with the response. For example, students who mentioned volcanoes and mountains in their answers as the primary cause of earthquakes received a score of 1 ; those mentioning plate tectonics received a score of 2; those with no or irrelevant answers received a score of 0 . Similarly, students' graphical responses (question 6 in the survey) were analysed using the evaluation rubric of Steer et al. (2005). For example, students' drawings of the Earth's interior were scored 0 (no conceptual framework) to 5 (advanced understanding). Students' scored responses to pre- and post-assessment questions were then analysed for comparison using a two-sample $t$ test when data followed the normal probability distribution and the non-parametric Kolmogorov-Smirnov (KS) test when the probability distributions were non-normal. For survey questions that required binary answers ("yes" or "no" responses, e.g. in questions 3-4 in the survey), we used the McNemar test to compare results. The significance level (alpha value) was set to 0.05 , and results were considered statistically significant if $p<0.05$.

\subsubsection{Video selection}

We selected three videos for classroom testing in the UK and Tajikistan. These videos included the first two earthquake science video lessons in the series (i.e. Earth's interior and plate boundaries) and the last earthquake hazard and safety video (i.e. non-structural hazards; see Fig. 3). These videos were chosen since they required no previous knowledge of earthquakes, and they cover the fundamental concepts related to earthquakes (i.e. Earth's interior and plate tectonics) and the most common cause of earthquake-related injuries (i.e. non-structural hazards). Furthermore, these videos use a wide range of pedagogical approaches to teaching and learning. For example, the Earth's interior video follows a modelbased, conceptual change approach to teaching to improve students' understanding of the Earth's structure, while the plate boundaries video is data driven and follows the jigsaw method of cooperative learning (i.e. students depend on each other to succeed), as shown in Sawyer et al. (2005). The nonstructural hazards video uses a place-based approach, promoting learning that is rooted in the students' own place (i.e. their classroom) to raise awareness about non-structural hazards and mitigation measures in school classrooms where the videos were tested. This range of teaching methods tested allows us to gain the most information about students' diverse and complex individual learning needs, in response to paired teaching, from the information collected in the questionnaires. 


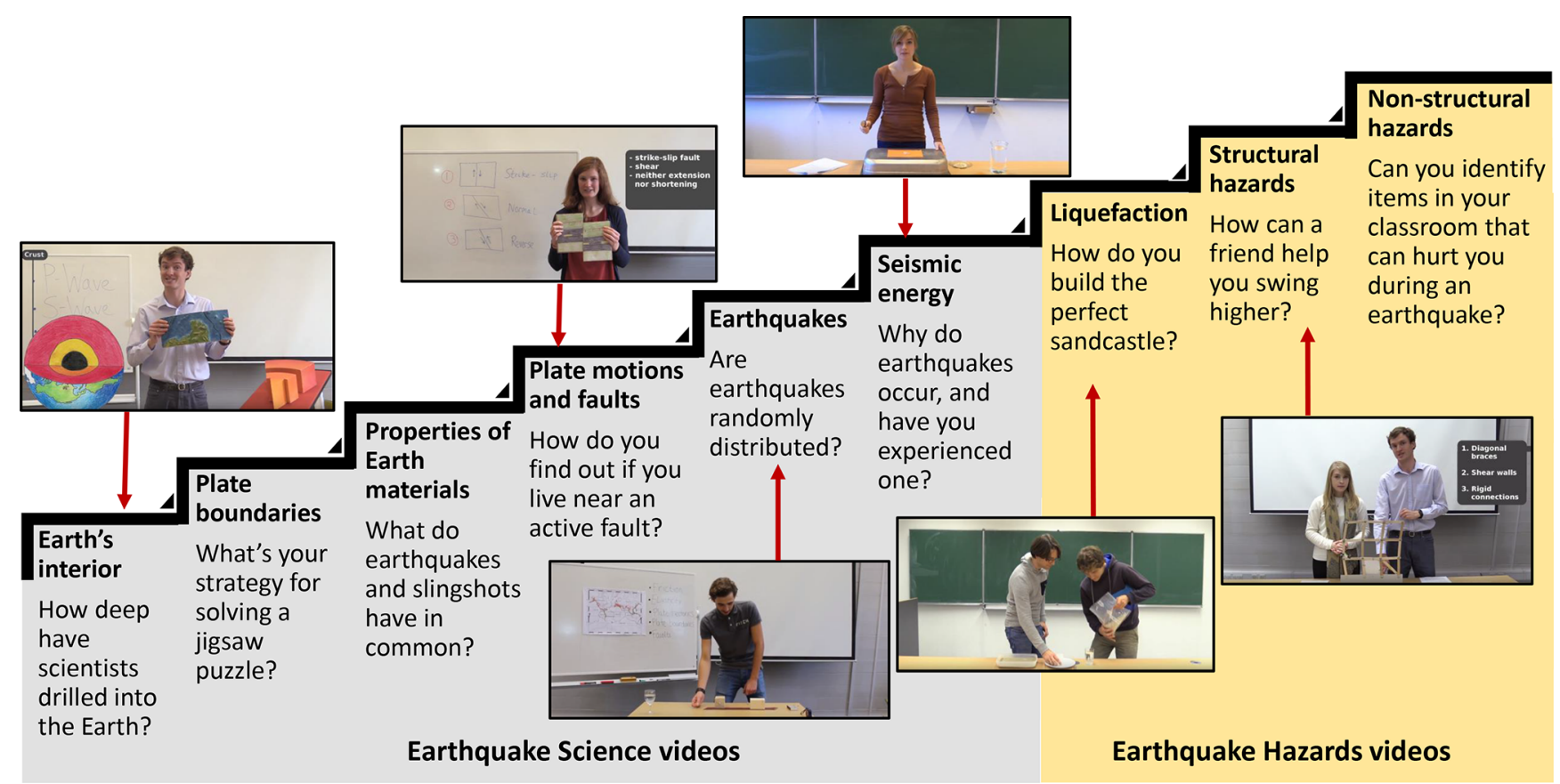

Figure 3. Stepwise earthquake education curriculum (modified from Mohadjer et al., 2010).

\subsubsection{School settings}

The three aforementioned videos were tested with 38 sixthgrade students (12 years of age; $50 \%$ female) and 39 ninthgrade students (12-14 years of age; $42 \%$ female) from two school classes in Dushanbe (Tajikistan) and London (United Kingdom), respectively. The school in Dushanbe (the capital city of Tajikistan) is a public school located in the city centre and was selected for this study by the Institute of Geology, Earthquake Engineering, and Seismology of Tajikistan because of its previous collaboration with Mohadjer et al. (2010). The school was recently built in compliance with the existing seismic building codes of Tajikistan. Interactive whiteboards are present in many of its classrooms, and there is a new computer lab with individual workstations. The video testing was conducted over $5 \mathrm{~d}$ during school hours (i.e. 08:00-12:00 local time - LT) by the lead author, with assistance from local teachers. The local language (Tajik) was used for teaching and in all written and multimedia materials, including the videos which were dubbed into Tajik. Resources needed for testing (e.g. maps, Slinky toys, and play dough) were provided by the lead author. The school in London (United Kingdom) is a secondary (11-18 years of age) academy located in the heart of the city. The London school was selected through our existing teachers' network in the UK. The videos were tested by two geography teachers with 1-3 years of teaching experience over a testing period of approximately $50 \mathrm{~d}$. The difference in the testing periods between the two schools was to accommodate different schedules teachers had to follow. While the UK teachers could spread out the video lessons across a $50 \mathrm{~d}$ period, the lead author of this paper had to follow a restricted schedule of $5 \mathrm{~d}$ for video testing in Tajikistan.

\section{Results}

Using the methods described in Sect. 2, we created 10 online video lessons. The videos were tested with school classrooms in Tajikistan and the United Kingdom during the 2018-2019 period. Below, we briefly introduce the videos and share the results of our classroom implementation.

\subsection{Paired-teaching video series}

Table 1 summarizes the teaching approach, topics covered, and classroom activities for each video, as well as the video duration and its digital object identifier (DOI). The video durations range from 12 to $24 \mathrm{~min}$ (excluding the teacher segment). In addition to our paired-teaching pedagogy, each video lesson incorporates a wide range of teaching strategies to create an active learning environment. While some strategies are based on group work methods, such as cooperative learning (as used in the Discovering Plate Boundaries video lesson), others include classroom experiments that involve students in collecting data, making predictions, and reflecting upon their observations (as shown in the Earthquake Machine video lesson). Most video lessons incorporate analogies and models to enhance conceptual understanding of some topics, such as Earth's interior structure and material properties, while allowing students to construct and cri- 
tique their models. All classroom activities are low-tech and require materials that can be easily obtained and assembled anywhere in the world.

\subsection{Video classroom testing}

To test the effectiveness of our paired-teaching technique, we selected and tested three video lessons with school students in Tajikistan and the United Kingdom. Since both groups watched the same videos and completed the same questionnaires prior to and after the testing of video lessons, full comparison of results between groups is possible. In the following sub-sections, we summarize students' responses to the six questions they were asked in the pre- and post-assessment surveys. The statistical test results are shown in the Supplement (Table S2).

\subsubsection{Students' understanding of the Earth's interior}

Students' understanding of the Earth's interior before and after the classroom testing of the Earth's Interior and Plate Tectonics video is shown in Fig. 4. While the majority of the Tajik students' responses, both before and after watching the video, show no to little understanding of the Earth's interior (scores of 0-2), responses given by the UK students are more evenly distributed between no or little understanding and higher levels of understanding (scores of $>2$ ). Both groups, however, show an increase in their understanding of the Earth's interior after watching the video. These observations are supported by statistical analysis of the results. More specifically, $74 \%$ of students (28 students) from Tajikistan and $48 \%$ from the UK (19 students) demonstrated having a no or a basic conceptual framework about the Earth's interior (scored 0-1) prior to video testing. After video testing, a large percentage of Tajik and UK students (58\% and 52\%, respectively) demonstrated an increased level of understanding of the Earth's interior (scored 3 or higher). The difference between Tajik students' responses before and after video testing was statistically significant (above $95 \%$ level), using the Kolmogorov-Smirnov (KS) test (D stat -0.31 ; D crit -0.30 ). Similarly, the difference between UK and Tajik students' responses before and after video testing was significant (above $95 \%$; D stat - 0.33; D crit -0.30).

\subsubsection{Students' understanding of causes of earthquakes}

We grouped students' responses into six categories (Fig. 5). In their responses to "What are the causes of earthquakes?", $90 \%$ (35 students) of the UK students mentioned plate tectonics, while $46 \%$ (17 students) of the Tajik students made references to mountains and volcanoes (with only 1 out of 38 students mentioning plate tectonics) before video testing. After video testing, the Tajik students showed little improvement in their understanding of the causes of earthquakes. The difference between UK and Tajik students' responses prior to video testing and their responses afterwards was significant, above the $95 \%$ level, using the KS test (D stat -0.84 and 0.79 ; D crit -0.30 and 0.30 ).

\subsubsection{Students' understanding of non-structural hazards}

Figure 6 shows the students' ability to identify non-structural hazards in example photographs. Non-structural earthquake hazards are caused by the furnishings and non-structural elements of a building (e.g. suspended ceilings and windows). In general, students from both groups identified nonstructural hazards that are located above the ground (e.g. hanging television set and plant pots stored above cabinets) and missed those near the floor (e.g. desks and chairs). Both groups demonstrated some knowledge of non-structural hazards found in typical school classrooms prior to video testing and showed some improvement after video testing. However, only the difference between pre- and post-assessment responses by the UK students was statistically significant above the $95 \%$ level, as indicated by the KS test (D stat 0.43; D crit - 0.30).

\subsubsection{Earthquake prediction}

Figure 7a shows students' responses to "Is it possible to know the exact timing of earthquakes before they occur?" While the majority of Tajik students indicate "no" in their responses before and after video watching $(55 \%$ and $68 \%$, respectively), UK students' responses are more evenly distributed between three categories of "no", "sometimes", and "I don't know" prior to video watching $(36 \%, 33 \%$, and $28 \%$, respectively) as well as after video testing (46\% indicate "no"; $38 \%$ indicate "sometimes"). After video watching, a notable percentage of Tajik students ( $21 \% ; 8$ students) believes that it is possible to know the exact timing of an earthquake.

In their pre-assessment responses to whether it is possible to know where an earthquake can occur (Fig. 7b), a significant percentage of both groups ( $47 \%$ - Tajik; $41 \%$ - UK) believe that is sometimes possible. After video watching, Tajik students' responses are divided almost evenly between the four different categories as follows: $26 \%$ (10 students) indicate that it is possible to know where earthquakes can occur ("yes" response), while $18 \%$ (7 students) believe otherwise ("no" response); $21 \%$ (8 students) indicate it is sometimes possible, and $26 \%$ (10 students) give irrelevant answers. In contrast, the majority of the UK students' post-assessment answers are "yes" to earthquake location prediction $(62 \%$; 24 students), with "sometimes" indicated in $28 \%$ (11 students) of responses. The differences between UK pre- and post-assessment responses is statistically significant above the $95 \%$ level, as indicated by the McNemar test (chi stat -6.66; chi crit - 3.84).

Additionally, we asked students the following open-ended question: where in the world do earthquakes occur most often? Based on their answers, we created five response cate- 
Table 1. Summary of the teaching approaches, topics covered, and classroom activities for each video, including the video duration and its digital object identifier (DOI).

\begin{tabular}{|c|c|c|c|c|}
\hline Title & Teaching approach & Topics covered & Main classroom activities & DOI and video length \\
\hline $\begin{array}{l}\text { Journey to the centre of } \\
\text { the Earth: Earth's inte- } \\
\text { rior and plate tectonics }\end{array}$ & $\begin{array}{l}\text { Conceptual model, } \\
\text { interactive lecture } \\
\text { demonstrations, and } \\
\text { use of analogies and } \\
\text { other visualize aids }\end{array}$ & $\begin{array}{l}\text { Earth's internal layers } \\
\text { and methods for in- } \\
\text { vestigating Earth's inte- } \\
\text { rior, including seismic } \\
\text { waves }\end{array}$ & $\begin{array}{l}\text { Using a hard-boiled egg as a } \\
\text { scale model for the layers of } \\
\text { the Earth; using Slinky toys } \\
\text { to model seismic waves; dis- } \\
\text { cussing model limitations }\end{array}$ & $\begin{array}{l}\text { https://doi.org/10.5446/47600; } \\
16 \text { min } \\
\text { (Mohadjer et al., 2017-2018a) }\end{array}$ \\
\hline $\begin{array}{l}\text { Living on the edge: dis- } \\
\text { covering plate bound- } \\
\text { aries }\end{array}$ & $\begin{array}{l}\text { Cooperative learning } \\
\text { (jigsaws), role playing, } \\
\text { and data-driven } \\
\text { exercises }\end{array}$ & $\begin{array}{l}\text { Linking plate bound- } \\
\text { ary processes to sci- } \\
\text { entific observations and } \\
\text { the scientific method }\end{array}$ & $\begin{array}{l}\text { Using data maps (e.g. earth- } \\
\text { quakes, volcanoes, seafloor age, } \\
\text { and topography) to investigate } \\
\text { plate tectonic boundary pro- } \\
\text { cesses }\end{array}$ & $\begin{array}{l}\text { https://doi.org/10.5446/47601; } \\
24 \text { min } \\
\text { (Mohadjer and Mutz, } \\
\text { 2017-2018b) }\end{array}$ \\
\hline $\begin{array}{l}\text { Soft rocks and hard } \\
\text { liquids: properties of } \\
\text { Earth materials }\end{array}$ & $\begin{array}{l}\text { Interactive lecture } \\
\text { demonstrations (using } \\
\text { everyday objects) }\end{array}$ & $\begin{array}{l}\text { Why and how materials } \\
\text { deform, and what con- } \\
\text { trols deformation and } \\
\text { energy transfer }\end{array}$ & $\begin{array}{l}\text { Applying force to everyday ob- } \\
\text { jects and observing and iden- } \\
\text { tifying factors influencing their } \\
\text { behaviour }\end{array}$ & $\begin{array}{l}\text { https://doi.org/10.5446/47700; } \\
13 \text { min } \\
\text { (Mohadjer et al., 2017-2018b) }\end{array}$ \\
\hline $\begin{array}{l}\text { Do you know your } \\
\text { faults? Plate motions } \\
\text { and faults }\end{array}$ & $\begin{array}{l}\text { Use of models and } \\
\text { teaching with visualiza- } \\
\text { tions (photos) and } \\
\text { art }\end{array}$ & $\begin{array}{l}\text { Causes and types of } \\
\text { plate tectonic stress and } \\
\text { resulting strain and the } \\
\text { mechanics of fault rup- } \\
\text { ture }\end{array}$ & $\begin{array}{l}\text { Using a dough to model Earth's } \\
\text { crust under stress and build- } \\
\text { ing different fault models using } \\
\text { pieces of cardboard }\end{array}$ & $\begin{array}{l}\text { https://doi.org/10.5446/47701; } \\
14 \text { min } \\
\text { (Mohadjer et al., 2017-2018c) }\end{array}$ \\
\hline $\begin{array}{l}\text { What causes that rock } \\
\text { 'n roll? The Earthquake } \\
\text { machine }\end{array}$ & $\begin{array}{l}\text { Classroom experiments } \\
\text { (building and operating } \\
\text { models) }\end{array}$ & $\begin{array}{l}\text { Earthquake mecha- } \\
\text { nisms, stick-slip } \\
\text { motion, and earthquake } \\
\text { prediction }\end{array}$ & $\begin{array}{l}\text { Operating a mechanical model } \\
\text { of a fault to observe fault mo- } \\
\text { tion during an earthquake, ex- } \\
\text { ploring the effects of several } \\
\text { variables, and discussing model } \\
\text { limitations }\end{array}$ & $\begin{array}{l}\text { https://doi.org/10.5446/47702; } \\
12 \mathrm{~min} \\
\text { (Mohadjer et al., 2017-2018d) }\end{array}$ \\
\hline $\begin{array}{l}\text { Rocking, rolling, and } \\
\text { bouncing: how do } \\
\text { earthquakes move the } \\
\text { Earth? }\end{array}$ & $\begin{array}{l}\text { Interactive, hands-on } \\
\text { demonstrations and } \\
\text { use of models and } \\
\text { animations }\end{array}$ & $\begin{array}{l}\text { Waves as energy trans- } \\
\text { fer, seismic waves, and } \\
\text { how they travel through } \\
\text { different materials }\end{array}$ & $\begin{array}{l}\text { Using a setup to show how } \\
\text { seismic waves can travel } \\
\text { through different materials and } \\
\text { modelling seismic waves using } \\
\text { Slinky toys and human bodies } \\
\text { (human waves) }\end{array}$ & $\begin{array}{l}\text { https://doi.org/10.5446/47703; } \\
21 \text { min } \\
\text { (Mohadjer et al., 2017-2018e) }\end{array}$ \\
\hline $\begin{array}{l}\text { Flow with the sand: in- } \\
\text { troduction to soil lique- } \\
\text { faction }\end{array}$ & $\begin{array}{l}\text { Classroom experi- } \\
\text { ments, using models } \\
\text { and visualizations }\end{array}$ & $\begin{array}{l}\text { Soil saturation and con- } \\
\text { solidation and causes } \\
\text { of soil liquefaction and } \\
\text { mitigation measures }\end{array}$ & $\begin{array}{l}\text { Building a liquefaction model } \\
\text { and using a shake table to test } \\
\text { its response to shaking }\end{array}$ & $\begin{array}{l}\text { https://doi.org/10.5446/47704; } \\
13 \text { min } \\
\text { (Mohadjer et al., 2017-2018f) }\end{array}$ \\
\hline $\begin{array}{l}\text { Safe or unsafe: non- } \\
\text { structural hazards } \\
\text { during earthquakes }\end{array}$ & $\begin{array}{l}\text { Place-based learning } \\
\text { and role playing }\end{array}$ & $\begin{array}{l}\text { Non-structural hazards } \\
\text { identification and miti- } \\
\text { gation, rapid visual } \\
\text { screening method, and } \\
\text { repair cost analysis }\end{array}$ & $\begin{array}{l}\text { Identifying non-structural haz- } \\
\text { ards in school classrooms and } \\
\text { discussing and proposing miti- } \\
\text { gation strategies }\end{array}$ & $\begin{array}{l}\text { https://doi.org/10.5446/47705; } \\
20 \text { min } \\
\text { (Mohadjer and Mutz, } \\
\text { 2017-2018c) }\end{array}$ \\
\hline $\begin{array}{l}\text { On shaky ground: } \\
\text { structural hazards } \\
\text { during earthquakes } \\
\text { (Part I) }\end{array}$ & Classroom experiments & $\begin{array}{l}\text { Introduction to the } \\
\text { shake table and how } \\
\text { different materials } \\
\text { respond to different } \\
\text { loads }\end{array}$ & $\begin{array}{l}\text { Constructing building models } \\
\text { and testing them on a shake ta- } \\
\text { ble and discussing model limi- } \\
\text { tations }\end{array}$ & $\begin{array}{l}\text { https://doi.org/10.5446/47706; } \\
13 \mathrm{~min} \\
\text { (Mohadjer et al., 2017-2018g) }\end{array}$ \\
\hline $\begin{array}{l}\text { On shaky ground: } \\
\text { structural hazards } \\
\text { during earthquakes } \\
\text { (Part II) }\end{array}$ & $\begin{array}{l}\text { Classroom experiments } \\
\text { and group discussions }\end{array}$ & $\begin{array}{l}\text { Earthquake engineering } \\
\text { of buildings with re- } \\
\text { spect to frequency, nat- } \\
\text { ural frequency, and res- } \\
\text { onance }\end{array}$ & $\begin{array}{l}\text { Constructing and testing build- } \\
\text { ing models on a shake table, } \\
\text { modifying them to reduce res- } \\
\text { onance, and discussing model } \\
\text { limitations }\end{array}$ & $\begin{array}{l}\text { https://doi.org/10.5446/47707; } \\
16 \text { min } \\
\text { (Mohadjer et al., 2017-2018h) }\end{array}$ \\
\hline
\end{tabular}




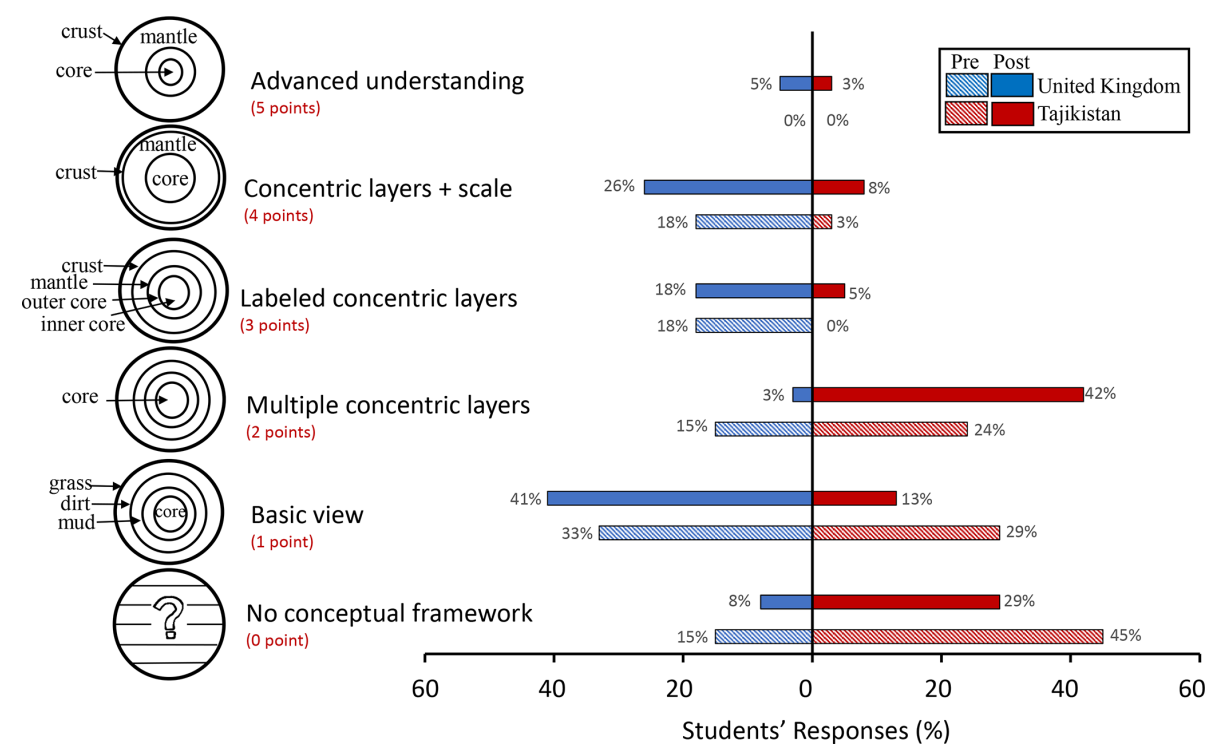

Figure 4. Students' understanding of Earth's interior (right) when asked to sketch a cross section of the Earth. The evaluation rubric is after Steer et al., 2005 (left).

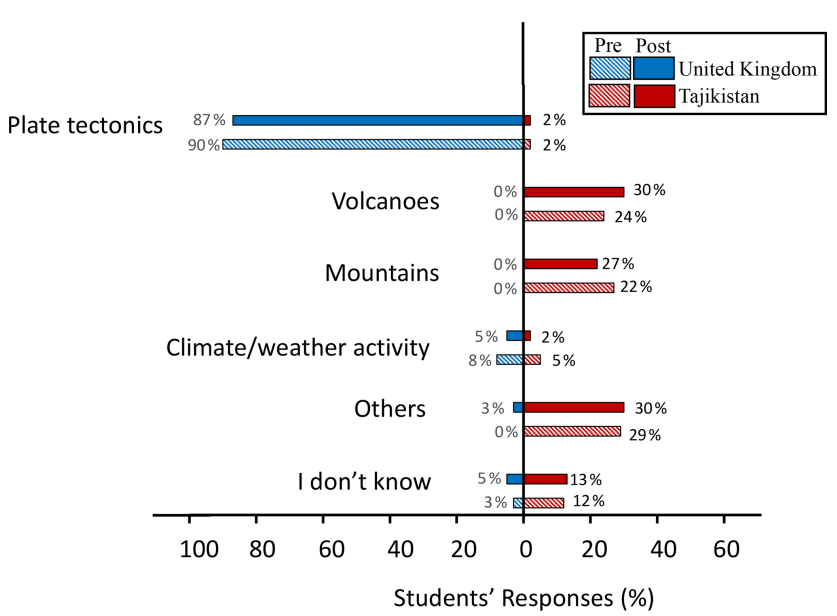

Figure 5. The causes of earthquakes, according to the students.

gories (Fig. 7c). A large percentage of students' responses from both groups include country names before and after watching the videos. UK students also included plate boundaries in their responses both before and after watching videos ( $21 \%$ and $40 \%$, respectively). In contrast, Tajik students made references to mountains or volcanoes (39\% and $44 \%$, respectively). These observations match students' responses to the causes of earthquakes (Fig. 5). The differences between UK and Tajik post-assessment responses is statistically significant above the $95 \%$ level, as indicated by the KS test (D stat -0.38 ; D crit -0.30 ).

\section{Discussion}

\subsection{Factors influencing students' learning}

The differences between students' pre- and post-assessment responses to survey questions were only significant above the $95 \%$ level when they were asked to indicate if it was possible to know where earthquakes happen (Sect. 3.2.4), to sketch a cross section of the Earth (Sect. 3.2.1), and to identify nonstructural hazards in example photographs (Sect. 3.2.3) (Table S2 in the Supplement). These results indicate that our paired-teaching videos appear to change students' views and understanding of some concepts, including (i) the Earth's interior for the Tajikistan group, (ii) earthquake location forecasting for both the Tajikistan and UK groups, and (iii) nonstructural hazards for the UK group. However, our curriculum did not significantly change students' understanding of other concepts, including causes of earthquakes and their relation to plate boundaries. Below, we discuss possible factors that improve or hinder students' learning of these targeted topics.

\subsubsection{Interior of the Earth}

While a notable percentage of Tajik students' responses (50\%, 19 students) indicate an increase of at least one score point in their understanding of the Earth's interior, only four (out of 38) students demonstrated an advanced understanding of the Earth's interior structure where scale is important (score 4-5). This is despite the fact that students were shown a diagram of a cross section of the Earth (with all layers drawn to scale and labelled) by the video teacher and participated in a classroom activity during which they com- 


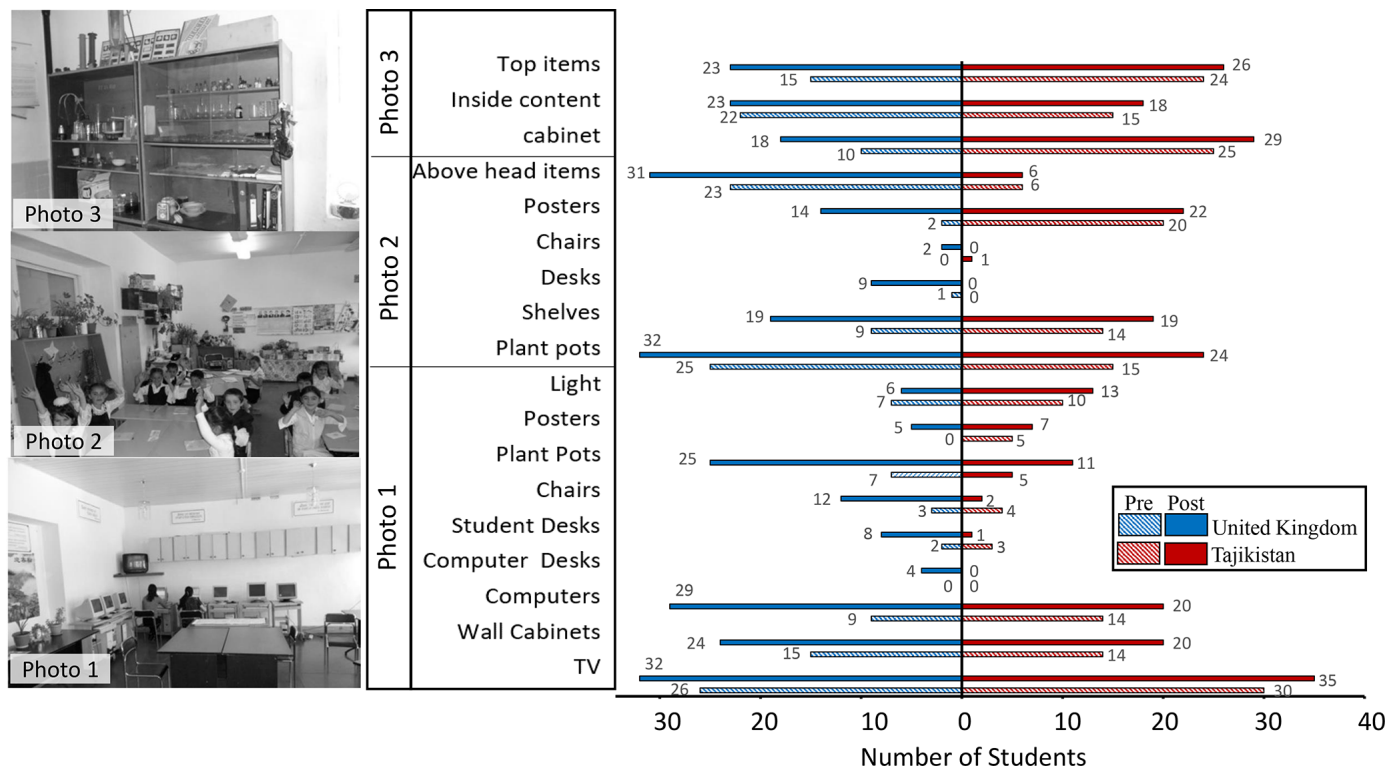

Figure 6. Students' understanding of non-structural hazards. From left to right: photographs used in questionnaires for non-structural hazard identification, items identified correctly as non-structural hazards, and pre- and post-assessment results. Photo credit: AKDN/DRMI, 2011 (https://www.akdn.org/, last access: 19 May 2021).

pared the interior structure of a hard-boiled egg with that of the Earth. These concepts, however, were unfamiliar to Tajik students prior to video testing and were not repeatedly reinforced during and after video implementation. It is important to note that more than $50 \%$ of Tajik students did not label the Earth's layers in both pre- and post-assessment surveys since this was not specified by the question. However, the post-assessment data show a $24 \%$ increase in the number of students who drew the interior of the Earth as concentric circles. Therefore, it is possible that students' understanding of the Earth's interior after video watching is underestimated. For the UK group, $46 \%$ (18 out of 39 students) showed no or a basic conceptual framework of the Earth's interior after video testing, with only $31 \%$ (12 students) showing some improvement. We, therefore, conclude that diagrams and simple analogies can bring some improvement to learning these concepts, but to make significant conceptual advances, concepts must be revisited and reinforced repeatedly.

\subsubsection{Causes of earthquakes}

The Earth's interior and plate boundary videos did not increase students' understanding of earthquakes and associated processes. After video testing, only one Tajik student (out of 38) listed plate tectonics as the main cause of earthquakes. The relationship between plate tectonics and earthquakes was briefly mentioned by the video teacher in the Earth's interior video. However, during the testing of the plate boundary video, students used different data sets (including an earthquake map) to observe data behaviour near or at plate boundaries. It is possible that the students' in- complete understanding of the Earth's interior structure (as described above) hindered their learning process associated with earthquakes, as shown by Barrow and Haskins (1996). Another hindering factor could be the lack of previous exposure and concept reinforcement during or after video testing. Relating earthquakes to volcanoes and mountains is part of students' pre-existing knowledge, as demonstrated in $39 \%$ to $50 \%$ of students' pre-responses to question 1 (i.e. "what are the causes of earthquakes?") and question 4 (i.e. "where in the world do earthquakes occur most often?"), respectively. Students' pre-existing knowledge of why and where earthquakes occur was revisited and reinforced in the plate boundary video and the accompanying classroom activities, where students explored relations between distribution of volcanoes, topography, and earthquakes. Relating these processes to plate boundaries, however, was a new concept that was not reinforced. Unlike previous work by Mohadjer et al. (2010), we documented no mention of myths, legends, or religious explanations in Tajik students' responses to causes of earthquakes. This could be due to (1) different data collection methods (anonymous survey questionnaires in this study vs. individual or group interviews in Mohadjer et al., 2010) and (2) differences in students' ages or grade level (the 2010 participants were 2-3 years older than the 2018 participants), and/or (3) this may be a reflection of changing earthquake perceptions over the last decade. In contrast, nearly all UK students (35 students) connect earthquake occurrence with plate tectonics prior to video watching. Because of their previous knowledge, it is difficult to assess the effectiveness of the plate boundary curricular activities conducted with this group. 


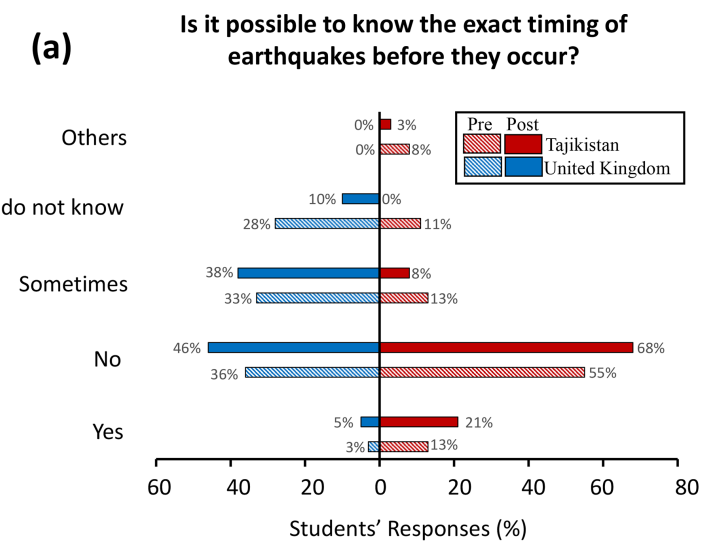

(b) Is it possible to know where
earthquakes can occur?

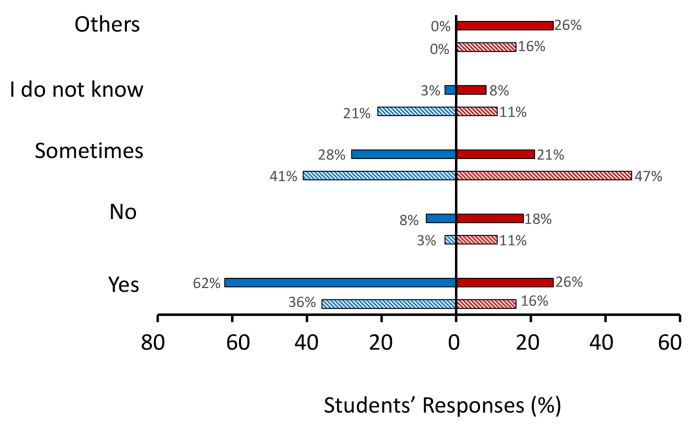

(c)

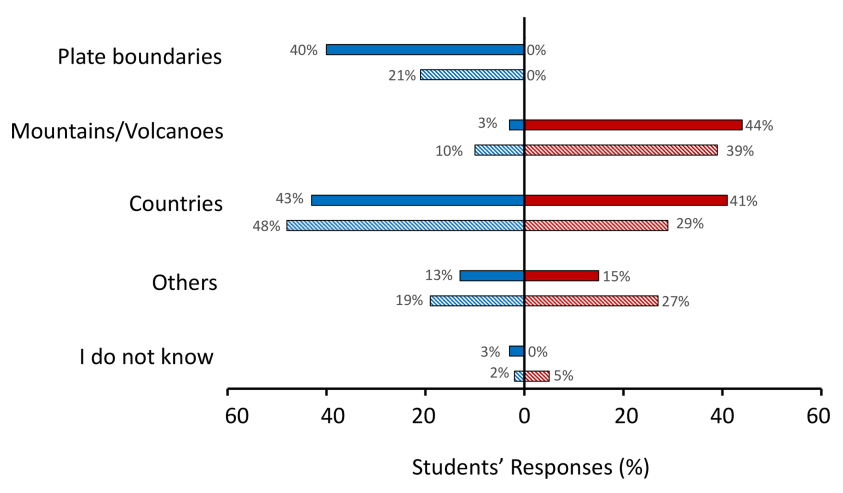

Figure 7. Students' understanding of earthquake prediction, including earthquake timing (a), location (b), and where in the world earthquakes occur most often (c).

\subsubsection{Earthquake prediction and forecasting}

The two closed questions in the survey that assessed the students' views of earthquake prediction (questions 2 and 3) in terms of earthquake location and timing were not directly addressed by our curricular material. However, these questions were selected to (1) assess the students' current perception of and views on earthquake prediction and forecasting in general and (2) to find out whether learning about the Earth's interior and earthquake-related processes alone can change the students' views of earthquake prediction and forecasting. This information is important, since earthquake prediction or forecast, or lack thereof, may influence preparedness attitudes and behaviours in some communities. Prior to video watching, approximately $60 \%$ (23 Tajik students) said "no" to earthquake prediction (in terms of date and time) and "yes" or "sometimes" to earthquake forecasting (in terms of location). In contrast, these values for the UK group are lower (36\%; 14 students) and higher (77\%; 30 students), respectively. The only significant difference (95\% level) between the students' pre- and post-answers was observed for the UK group for earthquake location forecasting. This may indicate that our curricular material (particularly the plate boundary classroom activity), which emphasizes that earthquake locations are not random, was effective in changing students' understanding of earthquake location forecasting. A notable portion of Tajik students ( $26 \% ; 10$ students), however, misinterpreted the survey question, as is evident in their irrelevant responses to earthquake location forecasting (e.g. listing streets and schools as locations of earthquakes).

\subsubsection{Non-structural hazards}

For both student groups, our non-structural hazard video increased the students' ability to identify non-structural hazards in example classroom photos. However, the increase in hazard identification is significant (95\% level) only for the UK group. This could be due to lack of exposure to earthquake shaking during which non-structural elements of a building can pose hazards to the building's occupants. Having experienced earthquakes and being familiar with some hazards, Tajik students' give similar responses before and after video watching.

\subsection{Teacher feedback \\ 4.2.1 UK teacher feedback}

Both teachers found the curricular material to be presented clearly, to be appropriately geared to the level of their students, and to be valuable in helping students understand and learn the lesson content. However, there were differences in how they rated the materials in terms of relevance. In general, classroom activities carried out during video breaks were described as relevant by both teachers. However, both teachers found activities related to the cost-benefit analysis of nonstructural hazards in video 3 to be irrelevant with low levels of student engagement when compared with other assignments in their class. One teacher explained, "[students] did not find the tasks that useful/applicable to life as we are not in an earthquake-prone area." Similarly, another teacher said, "[...] compared to the way we normally teach tectonic hazards, this (1 h $40 \mathrm{~min}$ ) felt like a lot of curriculum time on a relatively narrow aspect of the topic." There were some differences between teachers' opinions and experiences with video testing. For example, while one teacher found the egg 
analogy to be a "very relevant" activity and described students' level of engagement with this activity as being "a great deal more" than with other classroom assignments, the other teacher recommended omitting this activity, saying "[...] I think they could have completed this task more effectively without being given and cutting up the egg (which took up time and [was] a distraction)." Teachers played the entire videos in the classroom, with the exception of the plate boundary video for which one teacher played only two out of five video segments and skipped the related classroom activities. The same teacher described students' level of engagement to be below average for the two activities that were carried out.

\subsubsection{Tajik teacher feedback}

Video testing in Tajikistan had to be conducted by the lead author (a geosciences researcher and teacher) due to the local teachers' lack of interest and/or confidence in having the required teaching skills and knowledge. This was despite making teaching materials accessible and available in the local language in advance of video testing and holding an informal meeting with local teachers during which they were introduced to paired teaching and lesson content. To further support and encourage the local teachers to participate in the video testing, a trained teaching assistant familiar with the paired-teaching videos was made available. The school principal was supportive of teachers' participation but did not require it. Due to limited time and resources, we had to carry out the video testing with little contribution from local teachers. The teacher feedback discussed here, therefore, reflects our experience with video testing.

With the exception of the plate boundary video, the level of content covered in both the Earth's interior and nonstructural hazards videos were appropriate for Tajik students. During the plate boundary video testing, most students were not only challenged by the lesson content (e.g. understanding maps, data relationships, and classification) but also struggled with understanding and following the pedagogical approach (e.g. collaborative learning) required for classroom activities. This lowered the class pace, and therefore, the video was played partially, with some classroom activities omitted. Students' level of engagement was the lowest for the plate boundary video and the highest for the non-structural hazard video, which focused on a topic most student could relate to (identifying hazards in their own classroom). The level of student excitement with lessons, however, was the highest when watching the Earth's interior video, which was taught by a UK-based video teacher. The excitement was less for the subsequent videos, which were taught by the lead author who had to act as both the video teacher and the in-class teacher.

The video testing was affected by both the classroom testing period and the choice of space and place for curriculum implementation. For example, the Earth's interior video was tested during normal school hours but outside the classroom environment in Tajikistan. For this lesson, the stage in the school theatre was selected by school authorities because the equipment required (e.g. projector, screen, and sound system) was only available for use there. For the remaining two videos, the teaching space was changed to a regular classroom and a computer lab. While the latter restricted the students' movements and group formation for activities, the former provided a familiar and flexible space where the students and the in-class teacher could easily rearrange chairs and tables according to their needs. In addition, it is possible that the differences in the testing periods between the UK and Tajikistan groups ( $50 \mathrm{~d}$ vs. $5 \mathrm{~d}$, respectively) influenced the study results. For example, due to time constraints, some inclass activities had to be shortened or skipped in Tajik classrooms. That, combined with technological issues, posed additional challenges to video testing by shortening video testing period. Teacher feedback highlights some important differences and similarities during classroom video implementation in two geographically and culturally different parts of the world. As the above observations show, the students' experience with earthquakes and related hazards influences their level of engagement with lesson content. While technological shortcomings and ineffective classroom space and management significantly challenged video testing in Tajikistan, these factors were non-existent in the UK school. The poor classroom management in the Tajik school was exacerbated by the lack of the local teachers' involvement, which led them to bring in a new teacher (lead author) who was unfamiliar with the specifics of the classroom culture. Despite these differences, both the UK and Tajik teachers acted flexibly with video testing by modifying the video lessons according to the needs of their students and their local environment (e.g. skipping video segments irrelevant to students' lives or shifting to printed lesson plans and other resources when technology failed). To maximize the impact of our pairedteaching approach to earthquake education, we suggest exercising flexibility when using our videos and contextualizing video content and learning activities to increase their relevance. To encourage and assist teachers with lesson preparation, we plan to improve our teacher segment by creating a guide for each video, in a printable format, with descriptions of activities covered in each segment, as requested by UK teachers.

\subsection{Lessons learnt}

This study brought together a group of early career Earth scientists to develop and test a series of earthquake education video lessons to support school teachers with earthquake education worldwide. The paired-teaching technique provided an effective means for these scientists to connect and co-teach curricular materials with school teachers that might have not been able to invite, host, and co-teach lessons with them. In the case of Tajikistan, these lessons were im- 
plemented in a country that lacks the economic resources to develop and promote a school-based geohazards education (Mohadjer et al., 2010), despite a clear need for it. Therefore, our paired-teaching video lessons can be an effective way for Earth scientists worldwide to engage with school teachers, regardless of their locations (assuming language and technological barriers are addressed as it was the case in this study). Below, we discuss some of the lessons learnt in this study that will enable us to increase the impact of future Earth sciences education and outreach efforts taken by Earth scientists worldwide.

\subsubsection{Classroom culture}

An effective DRR-related, school-based education is one that is contextualized to meet local needs and carried out in the cultural context that surrounds the implementation of the curriculum. Students' and teacher's needs and goals, local constraints, and schools' pedagogical values are some of the factors that shape a classroom culture. While some topics, such as the Earth's interior and plate tectonics are often covered to varying degrees in most schools around the world, knowing how to identify and fix non-structural hazards related to earthquakes might not be as relevant to schools located in non-seismically active regions. Similarly, content taught using pedagogical approaches that are unfamiliar to some teachers and students can hinder effective learning. For example, most of the learning activities in this study were based on cooperative learning (e.g. jigsaw concept) and involved group discussions, where everyone's input was encouraged. Because they were unfamiliar with this approach, these activities appeared to be unstructured to most Tajik students, leaving some students being uncomfortable with sharing their opinions.

The low level of engagement by local teachers in Tajikistan, with respect to serving as in-class teachers in the paired-teaching approach, may be due to their unfamiliarity and discomfort with collaborative learning methods and the use of video technology. Since the paired-teaching video lessons were designed to be a complete resource (i.e. containing video segments, teacher's guides, downloadable handouts, and lists of other resources relevant to the topic), no teacher training was provided for using these videos. However, teachers were encouraged to view the videos and familiarize themselves with the content before using them in their classrooms. This study, however, reveals that these videos may not be seen as a complete resource by some teachers. While the UK teachers tested the videos with minimal input from video creators, teachers in Tajikistan asked to observe classroom testing of the videos. This request was made despite the fact that the teachers were offered training in delivering the videos and/or the option to co-teach the video lessons with experienced instructors. Similar to teachers in Tajikistan, teachers in China, Japan, and Malaysia, where rote learning dominates classroom culture, experienced dif- ficulties with paired teaching (Larson and Murray, 2017). Therefore, the textbook-based classroom culture may partly explain why Tajik teachers did not want to actively engage in video testing. In addition, teachers' low level of technology acceptance and readiness for teaching and learning has been shown to hinder their engagement with technologybased pedagogical approaches (Shukor et al., 2018). Our study, therefore, shows that the paired-teaching pedagogy is not a one-size-fits-all teaching approach and depends on the classroom culture and teacher's comfort operating within it. Thus, when developing curricular material, both teachers' and students' involvement are key to ensure an appropriate selection of content and pedagogical approaches. This can be achieved through informal classroom observation and discussions of goals and pedagogical expectations with classroom teachers and students, as well as providing ongoing, highquality pedagogical training that supports teachers in adopting a more student-centred and collaborative teaching style for their classrooms.

\subsubsection{Curriculum evaluation}

The importance of public engagement activities is increasingly recognized by scientists, funding institutions and policymakers (NSF, 2015; Rauws, 2015; European Union, 2002). However, many of those who practice science education and outreach do not always evaluate their work rigorously, and even fewer publish and share their results in peer-reviewed journals. By testing our videos in school classrooms located in different countries (UK and Tajikistan), we were able to assess the effectiveness of our educational materials and identify potential factors that influence learning. However, the assessment of our evaluation strategy revealed several issues. While using questionnaires with students may be a time and/or cost-efficient method of collecting information anonymously, if not designed and explained carefully, the students may interpret the questions differently. This was the case with some students in Tajikistan, where they perceived the questionnaire as an exam and strived for correct answers as opposed to freely sharing their existing knowledge. Despite gaining new knowledge, some Tajik students gave identical responses to pre- and post-assessment questions in order to be consistent as opposed to being correct. We, therefore, recommend using questionnaires as one of several methods for collecting and evaluating data. Strategies such as conducting face-to-face interviews with students or arranging for and recording group interviews can minimize misunderstanding and provide important insights into student-student and student-teacher interactions that enhance or hinder learning. Thus, an effective evaluation strategy should consider students' familiarity with data collection methods to ensure that the students understand what they are being asked to do and why. 


\section{Conclusions}

In this study, we created 10 geoscience video lessons focusing on earthquake science and hazards. The paired-teaching approach was used to engage geoscientists as video teachers who introduce and discuss concepts in brief video segments. In between segments, these concepts were explored through hands-on activities under the guidance of an in-class teacher. We tested three videos (Earth's interior, plate boundaries, and non-structural hazards) with a total of 77 students (12-14 years of age) from schools in Dushanbe (Tajikistan) and London (United Kingdom). Our analysis of the students' pre- and post-assessment responses to survey questions indicate the following: (1) students' pre-existing conception about the causes of earthquakes is difficult to modify if new concepts are not repeatedly reinforced, and (2) students' incomplete understanding of the Earth's interior hinders their learning process associated with earthquakes. Comparison of results from the UK and Tajikistan groups reveal significant differences between students' views on the Earth's interior and why and where earthquakes generally occur. Possible factors influencing students' learning are those related to students' own experience with earthquakes, pre-existing knowledge, and unfamiliarity with some content (e.g. data maps) and pedagogical approaches (e.g. collaborative learning). These factors should be taken into account in order to maximize students' learning during paired teaching.

Despite documenting an increase in students' understanding of some concepts covered in the tested videos, the effectiveness of our entire video series cannot be fully assessed without furthering testing. This is because the series follows a stepwise approach to increasing students' understanding of earthquake science and hazards, with later lessons in the series building on topics covered in earlier lessons. This approach allows for the reinforcement of some difficult concepts. However, excessive workload, a restrictive curriculum, and increased pressure to achieve good results limit teachers' decisions to use the entire series, which includes 10 videos (total of 10-20 h of classroom time). Therefore, we recommend selecting and using video segments that are relevant to (and can enhance) the teaching of specific topics covered by an existing curriculum. In addition, our videos can serve as a resource for teachers who cannot easily arrange for an inperson or a virtual live session between their students and an Earth scientist.

Geoscience and natural hazard researchers' contribution to developing resilient communities is often through engagement in disaster risk reduction (Gill et al., 2021). We hope that lessons learnt in this study can benefit the scientific and wider DRR community by highlighting some of the key factors that influence the teaching and learning of geohazard content. There is already a wide range of tools and resources developed by the geohazard community to ensure meaningful access to scientific information relevant to DRR. Examples include Hazard Ready (a hazard preparedness web ap- plication developed by MacPherson-Krutsky and Bendick, 2019), the Central Asia Fault Database (a searchable repository of active fault and earthquake information by Mohadjer et al., 2016), and various earthquake data products created by the Global Earthquake Model team (e.g. the Global Seismic Hazard Map shown in Fig. 1). These resources, if contextualized appropriately, can be effectively incorporated into DRR educational materials (e.g. our paired-teaching videos, animations, and exercises) used with the K-12 and higher education communities.

Video supplement. All video files are archived and available for download at the Technische Informations Bibliothek (TIB) AV-Portal (https://av.tib.eu/series/867/earthquake+education, Mohadjer and Mutz, 2017-2018a). Please find a detailed list of the videos in Table 1 . In addition, the videos are available for view on the YouTube channel of the European Geosciences Union (https://www.youtube.com/user/EuroGeosciencesUnion, last access: 21 May 2021).

Supplement. The supplement related to this article is available online at: https://doi.org/10.5194/gc-4-281-2021-supplement.

Author contributions. SM and SGM were responsible for the video production, direction, and editing and planning of the study. Videos evaluated in this study were presented by MK and SM. Classroom testing of videos in Tajikistan was coordinated by AI and led by SM. MK and SJG arranged and coordinated the video testing in the UK school. Data analysis was done by SM and SGM. All authors contributed to the preparation of the paper.

Competing interests. The authors declare that they have no conflict of interest.

Acknowledgements. We thank Ruth Amey, Jessica Starke, Lewis Mitchell, Reinhard Drews, and Matthias Nettesheim, for helping with the video presentation and filming. We are grateful to Joel Gill, Bruce Malamud, Jordan-Cyrus Seyedi, Charlotte Jackson, and Faith Taylor, for coordinating and assisting with the video filming in London. We also thank Richard Larson, Elizabeth Murray, and Natalie Glynn, for the helpful discussions. We would like to express our appreciation to the principals, teachers, and staff members of schools selected for this study and our appreciation for the ongoing collaboration with the Institute of Geology, Earthquake Engineering, and Seismology in Tajikistan. The paper benefited from constructive comments by Anna Hicks and one anonymous reviewer. We thank Katharine Welsh for the editorial handling.

Financial support. This research has been supported by the European Geosciences Union public engagement grant and by the CAME II project bundle CaTeNA of the German Federal Ministry of Education and Research (BMBF; grant no. 03G0878D). 
Review statement. This paper was edited by Katharine Welsh and reviewed by Anna Hicks and one anonymous referee.

\section{References}

Barrow, L. and Haskins, S.: Earthquake Knowledge and Experiences of Introductory Geology Students, Journal of College Science Teaching, 26, 143-146, 1996.

Bilham, R. and Gaur, V.: Buildings as weapons of mass destruction, Science, 341, 618-619, https://doi.org/10.1126/science.1238476, 2013.

Bybee, R. W., Taylor, J. A., Gardner, A., Scotter, P. V., Powell, J. C., Westbrook, A., and Landes, N.: The BSCS 5E Instructional Model: Origins, Effectiveness, and Applications, Colorado Springs, CO: BSCS, 2006.

Cavlazoglu, B. and Stuessy, C.: Changes in science teachers' conceptions and connections of STEM concepts and earthquake engineering, J. Educ. Res., 110, 239-254, https://doi.org/10.1080/00220671.2016.1273176, 2017.

Erdik, M. and Durukal, E.: Earthquake risk and its mitigation in Istanbul, Nat Hazards, 44, 181-197, https://doi.org/10.1007/s11069-007-9110-9, 2008.

European Union: Science and society: Action plan. Luxembourg: Office for Official Publications of the European Communities, available at: https://ec.europa.eu/research/swafs/pdf/pub_ gender_equality/ss_ap_en.pdf (last access: 1 February 2021), 2002.

Gill, J. C., Taylor, F. E., Duncan, M. J., Mohadjer, S., Budimir, M., Mdala, H., and Bukachi, V.: Invited perspectives: Building sustainable and resilient communities - recommended actions for natural hazard scientists, Nat. Hazards Earth Syst. Sci., 21, 187202, https://doi.org/10.5194/nhess-21-187-2021, 2021.

Halvorson, S. J. and Hamilton, J. P.: Vulnerability and the erosion of seismic culture in mountainous Central Asia, Mt. Res. Dev., 27, 322-330, https://doi.org/10.1659/mrd.0900, 2007.

Halvorson, S. J. and Hamilton, J. P.: In the aftermath of the Qa'yamat: 1 the Kashmir earthquake disaster in northern Pakistan, Disasters, 34, 184-204, https://doi.org/10.1111/j.14677717.2009.01124.x, 2010.

Larson, R. C. and Murray, M. E.: STEM Education: Inferring Promising Systems Changes from Experiences with MIT BLOSSOMS, Syst. Res. Behav. Sci., 34, 289-303, https://doi.org/10.1002/sres.2411, 2017.

Lownsbery, D. S. and Flick, L. B.: Examining middle school students' knowledge and beliefs about earthquake and tsunami, Journal of Geoscience Education, 68.4, 311-323, https://doi.org/10.1080/10899995.2019.1707587, 2020.

MacPherson-Krutsky, C. and Bendick, R.: HazardReady: Disaster Preparedness Tools, HazardReady, LLC, available at: https: //hazardready.org/, last access: 19 May 2021.

MIT BLOSSOMS: https://blossoms.mit.edu/videos/create_your_ video, last access: 19 May 2021.

Mitchell, T., Tanner, T., and Haynes, K.: Children as agents of change for Disaster Risk Reduction: Lessons from El Salvador and the Philippines, Children in a changing climate research, Institute of Development Studies and Plan International, Brighton, UK, Working paper No. 1, 2009.
Mohadjer, S. and Mutz, S. G.: Paired teaching earthquake education video series, available at: https://av.tib.eu/series/867/earthquake+ education (last access: 21 May 2021), 2017-2018a.

Mohadjer, S. and Mutz, S.: Living on the edge: Discovering plate boundaries, episode 2, Earthquake education, TIB, https://doi.org/10.5446/47601, 2017-2018b.

Mohadjer, S. and Mutz, S.: Safe or unsafe? Non-structural hazards during earthquakes, episode 8, Earthquake education, TIB, https://doi.org/10.5446/47705, 2017-2018c.

Mohadjer, S., Bendick, R., Halvorson, S. J., Saydullaev, U., Hojiboev, O., Stickler, C., and Adam, Z. R.: Earthquake emergency education in Dushanbe, Tajikistan, Journal of Geoscience Education, 58, 86-94, https://doi.org/10.5408/1.3534854, 2010.

Mohadjer, S., Ehlers, T. A., Bendick, R., Stübner, K., and Strube, T.: A Quaternary fault database for central Asia, Nat. Hazards Earth Syst. Sci., 16, 529-542, https://doi.org/10.5194/nhess-16529-2016, 2016.

Mohadjer, S., Mutz, S. G., and Kemp, M.: Journey to the Center of the Earth: Earth's interior and plate tectonics, episode 1, Earthquake education, TIB, https://doi.org/10.5446/47600, 2017-2018a.

Mohadjer, S., Mutz, S., Drews, R., and Nettesheim, M.: Soft rocks and hard liquids: Properties of Earth materials, episode 3, Earthquake education, TIB, https://doi.org/10.5446/47700, 2017-2018b.

Mohadjer, S., Mutz, S., and Amey, R.: Do you know your faults? Plate motions and faults, episode 4, Earthquake education, TIB, https://doi.org/10.5446/47701, 2017-2018c.

Mohadjer, S., Mutz, S., and Mitchell, L.: What causes that Rock'n'Roll? The earthquake machine, episode 5, Earthquake education, TIB, https://doi.org/10.5446/47702, 2017-2018d.

Mohadjer, S., Mutz, S., and Starke, J.: Rocking, rolling and bouncing: How do earthquakes move the Earth?, episode 6, Earthquake education, TIB, https://doi.org/10.5446/47703, 2017-2018e.

Mohadjer, S., Mutz, S., Nettesheim, M., and Drews, R.: Flow with the sand: Introduction to soil liquefaction, episode 7, Earthquake education, TIB, https://doi.org/10.5446/47704, 2017-2018f.

Mohadjer, S., Mutz, S., Kemp, M., and Gill, S.: On shaky ground: Structural hazards during earthquakes (Part 1), episode 9, Earthquake education, TIB, https://doi.org/10.5446/47706, 2017-2018g.

Mohadjer, S., Mutz, S., Gill, S., and Kemp, M.: On shaky ground: Structural hazards during earthquakes (Part 2), episode 10, Earthquake education, TIB, https://doi.org/10.5446/47707, 2017-2018h.

National Geophysical Data Center/World Data Service (NGDC/WDS): Significant Earthquake Database, National Geophysical Data Center, NOAA, https://doi.org/10.7289/V5TD9V7K, last access: 3 March 2020.

NSF (National Science Foundation): Perspectives on broader impacts. Washington, DC., available at: https://www.nsf.gov/od/ oia/publications/Broader_Impacts.pdf, last access: 1 February 2021.

Oktari, R. S., Shiwaku, K., Munadi, K., and Shaw, R.: Enhancing community resilience towards disaster: The contributing factors of school-community collaborative network in the tsunami affected area in Aceh, Int. J. Disaster Risk Reduct., 29, 3-12, 2018. 
Pagani, M., Garcia-Pelaez, J., Gee, R., Johnson, K., Poggi, V., Styron, R., Weatherill, G., Simionato, M., Viganò, D., Danciu, L., and Monelli, D.: Global Earthquake Model (GEM) Seismic Hazard Map (version 2018.1 - December 2018), https://doi.org/10.13117/GEM-GLOBAL-SEISMICHAZARD-MAP-2018.1, 2018.

Paradise, T. R.: Perception of earthquake risk in Agadir, Morocco: A case study from a Muslim community, Global Environ. Change Part B, 6, 167-180, https://doi.org/10.1016/j.hazards.2006.06.002, 2005.

Pazzi, V., Morelli, S., Pratesi, F., Sodi, T., Valori, L., Gambacciani, L. and Casagli, N.: Assessing the safety of schools affected by geo-hydrologic hazards: the geohazard safety classification (GSC), Int. J. Disast. Risk Re., 15, 80-93, https://doi.org/10.1016/j.ijdrr.2015.11.006, 2016.

Rauws, G.: Public engagement as a priorty for research, in: Science, Society and Engagement, edited by: Edward Andersson, S. B. and Davis, H., An e-anthology, The Engage2020 Consortium, pp. 22-24, 2015.

Sawyer, D. S., Henning, A. T., Shipp, S., and Dunbar, R. W.: A data rich exercise for discovering plate boundary processes, Journal of Geoscience Education, 53, 65-74, https://doi.org/10.5408/10899995-53.1.65, 2005.

Selby, D. and Kagawa, F.: Disaster risk reduction in school curricula: case studies from thirty countries, United Nations Children Fund/United Nations Educational, Scientific and Cultural Organization, Geneva/Paris, 2012, available at: https://www.unicef.org/environment/files/ DRRinCurricula-Mapping30countriesFINAL.pdf (last access: 19 May 2021), 2012.

Sharma, K, Deng, L., and Noguez, C. C.: Field investigation on the performance of building structures during the April 25, 2015, Gorkha earthquake in Nepal, Eng. Struct., 121, 61-74, https://doi.org/10.1016/j.engstruct.2016.04.043, 2016.
Shukor, N. A., Abdullah, Z., and Mamad, N.: Teachers' Perception of Using STEM Video for Teaching and Learning, in: Proceedings of the 26th International Conference on Computers in Education, Philippines: Asia-Pacific Society for Computers in Education, edited by: Mercedes, M., Rodrigo, T., Yang, J. C., Wong, L. H., and Chang, M., 784-789, 2018.

Simpson, E.: Blame narratives and religious reason in the aftermath of the 2001 Gujarat Earthquake, South Asia: Journal of South Asian Studies, 34, 421-438, https://doi.org/10.1080/00856401.2011.620554, 2011.

Steer, D. N., Knight, C. C., Owens, K. D., and McConnell, D. A.: Challenging students' ideas about Earth's interior structure using a model-based, conceptual change approach in a large class setting, Journal of Geoscience Education, 53, 415-421, https://doi.org/10.5408/1089-9995-53.4.415, 2005.

Subedi, S., Hetényi, G., and Shackleton, R.: Impact of an educational program on earthquake awareness and preparedness in Nepal, Geosci. Commun., 3, 279-290, https://doi.org/10.5194/gc-3-279-2020, 2020.

Twigg, J.: Characteristics of a disaster-resilient community: a guidance note (version 2), available at: https://discovery.ucl.ac.uk/id/ eprint/1346086/1/1346086.pdf (last access: 23 October 2020), 2009.

UNICEF: Towards a learning culture of safety and resilience: Technical guidance for integrating disaster risk reduction in the school curriculum, United Nations Educational, Scientific and Cultural Organization (UNESCO), 2014.

Wisner, B.: The right to safety: building safe schools for children, UN Chronicles, 4, 59-60, 2005.

Yari, A., Zarezadeh, Y., and Ostadtaghizadeh, A.: Prevalence of fatalistic attitudes toward earthquake disaster risk management in citizens of Tehran, Iran, Int. J. Disast. Risk Re., 38, 101181, https://doi.org/10.1016/j.ijdrr.2019.101181, 2019. 